\title{
Patterns of Interaction in a Computer Conference Transcript
}

\author{
Patrick Fahy \\ Gail Crawford \\ Mohamed Ally
}

\begin{abstract}
An analysis of the interaction patterns in an online conference from a distance education graduate course was conducted, using an approach that focused on the transcript's interactional and structural features. A new tool for transcript analysis, the TAT (Transcript Analysis Tool), was used to analyze interactional features, while structural elements suggested by social network theory were examined. Analysis of the patterns of interaction in the conference showed interaction was variable, and that while all participants were engaged, intensity and persistence of participation were unequal among individual participants in several ways. The TAT showed the proportions of five major types of sentences in the transcript, corresponding to different modes of interaction (questions, statements, reflections, engaging comments, and quotations/citations). The findings showed that the TAT seemed to relate usefully to other work in this area, and that social network principles were valuable in the analysis of conference interaction.
\end{abstract}

\section{Introduction}

Text-based computer conferencing often provides the primary means for interaction and the search for consensus or new knowledge in distance education (Collins \& Berge, 1996; Morris, Mitchell \& Bell, 1999). Computer - mediated communications (CMC) researchers have studied a variety of outcomes and processes, including the dynamics at work among students (Henri, 1992); overall and personal interaction (Fulford \& Zhang, 1993); the creation and testing of meaning and new knowledge (Anderson \& Garrison, 1995; Zhu, 1996); the impact of modeling, coaching and scaffolding on the learning of new behaviours (Collins, 1996; Jonassen, 1999); integrated thinking (Gibson, 1996); negotiation of meaning and co-creation of knowledge through social interchange (Gunawardena, Lowe \& Anderson, 1997; Kanuka \& Anderson, 1998); and social presence (Rourke, Anderson, Garrison \& Archer, 1999). 
Despite this research record in transcript analysis, however, substantial gaps persist in our understanding of online interaction, both in relation to what transpires interactionally in conferences, and what factors contribute to a successful online experience from the participant's point of view. For researchers, these gaps indicate lack of a theoretically adequate account of learner-learner interaction in online situations (Anderson \& Garrison, 1995), and, for practitioners, the need for a model for managing online communications effectively. Redressing such omissions may at least partially require rethinking the methods of enquiry typically employed in transcript research. The increasing availability of tools for interaction may be expected to drive increased use of methods which employ them. Practitioners and researchers must be able to describe online interaction more than impressionistically, and measure effects more than anecdotally.

In this study we employed a new tool, the TAT, and techniques from social network theory applicable to transcripts to address problems of description and measurement in online interaction. The exploratory study attempted to address analytic issues by considering both content and structure in a computer conference transcript, focusing on the network exchange patterns observed in a conference transcript (Ridley \& Avery, 1979). The study shares Henri's (1992) view that a conference transcript is "a gold mine of information concerning the psycho-social dynamics" among the participants (p. 118). Pertinent to the study were the patterns of interpersonal exchange which develop over time in network transactions and which both characterize and apparently motivate network membership and participation (Ridley \& Avery, 1979). Understanding these patterns may enable instructors to address some fundamental gaps in our knowledge of online communications; focus on patterns and structures may also encourage a different perspective on the interaction process itself.

\section{Theoretical context}

The study was exploratory in that it made extended use for the first time of a new analytic tool, the TAT (Transcript Analysis Tool). Reasons for offering this new tool (described in detail in Attachment A) are discussed below. We analyzed the content of an online computer conference using the TAT, and viewed structural patterns in relation to selected elements of network theory. We hypothesized that analysis of both the patterns of exchange and the content might provide a richer assessment of the resulting interaction.

We defined interaction as "the totality of interconnected and mutually-responsive messages" (Gunawardena et al., 1997, p. 407; emphasis supplied). We see in this definition the wisdom of a holistic approach to transcript analysis - what Gunawardena et al. call the "entire gestalt" (p. 407) of the communicative situation. Viewed in this way, the communicative whole (content and structure) might well be greater than the sum of the individual postings.

International Review of Research in Open and Distance Learning 
A social network was defined as those individuals with whom a person is in some sort of regular, sustained contact (Ridley \& Avery, 1979). People normally belong to different social networks, reflecting personal and situational differences such as gender, age, place of residence, education, occupation, income, opportunity, and physical mobility. Social networks contain and are sustained both by content (ideas, opinions, information), and by the purely (or mainly) social interaction opportunities they offer. Social networks link likeminded people, allowing information and viewpoints to move among them. The computer conference in this study was regarded for theoretical purposes as a specialized social network.

Networks have long been known to be influential in human communications and interaction (Ridley \& Avery [1979, p. 224] describe the literature on networks as "vast"), which explains why networks for interpersonal interaction and exchange feature prominently in distance study (Collins \& Berge, 1996; Fulford \& Zhang, 1993; Garrison, 1989; Haughey \& Anderson, 1998). It seems plausible that by using some of the tools other disciplines have developed to understand the social structure of recurrent interaction, the study of online communication could provide greater understanding of the relational forms which emerge from uses of online computer conferences for learning (Burt, 1983).

Because of the growth in the number and variety of online networks in distance teaching, greater understanding of electronic communication is increasingly timely, even urgent. Another reason for concern with network processes is the fact that the exchange patterns - the recurrent transactions which begin to characterize the interaction among specific members or subgroups - may not be positive in all cases. Exchange patterns can and do range from benevolent to openly hostile (Ridley \& Avery, 1979), and may, in the worst cases, include serious problems such as addictive behaviour, rudeness and asocial interaction, and other forms of abuse of the medium or its related technologies (Abrami \& Bures, 1996; Collins, 1996; "One-third of workday," 2000). In the best cases, the exchange patterns reveal a partnership attitude among the participants in the learning process (Ridley \& Avery, 1979), but it is by no means uncommon for examination of network exchanges to reveal evidence of dislike and varying degrees of antagonism (Wellman, 1982).

The network concepts chosen for examination in this study were the structural and interactional exchange patterns observed in a transcript of a graduate distance education course. Structural features of interest in the investigation included the physical dimensions of the network, and the potential and actual levels of interaction revealed by the following (Ridley \& Avery, 1979):

- The size (number of members) and potential complexity of the network.

- The density (the ratio of the actual numbers of links to the possible total) and intensity (responsiveness and attentiveness of members to each other). 
Interactional features found in an analysis of the postings which comprise the conference transcript include:

- The kinds of content exchanged in the interaction (an indication of the members' perceptions of the learning element of the social relationship).

- The exchange flow or the directedness of the resulting interaction (an indication of the degree to which exchanges were symmetrical or asymmetrical; equal, unequal, or complementary).

\section{Design of the study}

Before embarking on an analysis of the interactional and structural elements of the transcript, the problem arose of choosing a tool and procedure for analyzing transcript content. In a previous paper (Fahy, 2001a), problems with past transcript analysis approaches were examined. To explain our proposed solution, the TAT, we summarize these briefly here.

1. Reliability. Transcript studies often omit entirely any mention of reliability (Gibson, 1996; Rourke, et al., 1999), or admit that reliability was achieved only by resorting to inefficient strategies such as collaborative coding (Kanuka \& Anderson, 1998). If a classification system for analysis of transcripts is to be useful for various purposes to practitioners of online communication, reliability is essential. Reports of reliability permit users to assess the probable accuracy or the additional resources needed to achieve accuracy with various systems. In this study, a combination of intra- and inter-rater reliability tests was used (described below) to arrive at an estimate of the instrument's reliability for content analysis.

2. Lack of discriminant capability of instruments. Some previously used analytic approaches and tools have been acknowledged by their developers as failing to discriminate adequately among the types of statements appearing in transcripts. A major problem was that large portions of the transcript were coded into a very few interaction categories (Gunawardena et al., 1997; Kanuka \& Anderson, 1998; Zhu, 1996), with the result that the transcript's communicative richness may not have been fully revealed.

3. Excessive numbers of coding categories. Somewhat ironically, given the previous point, it has also been common for coding instruments to employ numerous categories (up to 20 coding categories have been encountered, and the average among 5 popular instruments was 14). Users are thus forced to make very fine discriminations in using the instrument - finer than may be reliably replicated by others (Cookson \& Chang, 1995; Fahy, 2001a; Rourke, et al., 1999). Overly-complex tools make unreasonable 
demands on users. If fewer categories are used, and these focus on the most important and common types of interactions engaged in by the conference participants, it may be easier for coders to make classification decisions, and for readers to interpret the results.

4. The definition of meaning. Many transcript postings obviously contain more than one unit of meaning (Gunawardena et al., 1997; Henri, 1992). Attempts to find and code the meaning of whole postings falter at this point, or result in the invention of new constructs of doubtful provenance such as "speech segments" (Gibson, 1996) or "units of meaning" (Henri, 1992).

In this study, we deliberately separated the unit of meaning from the unit of analysis. In choosing sentence types for analysis with the TAT, we sought to focus on the text, including the context in the form of the structural elements provided in the conferencing format. Focus on the types of sentences and structural features of conferences was motivated by an obvious (to us) fact about online communication: transcripts are made up of text, organized by the writer (or speaker) into sentences. The resulting message is then intentionally placed (posted) by its creator at a particular point within the conference structure, related by its placement to the ongoing online discussion. The process makes the sentences and paragraphs, their placement, and the interrelation of these and other elements of the resulting transcript potentially important indicators of and contributors to the meaning of the exchange.

\section{Questions}

Two questions were posed for exploration in this study:

- What interactional and structural exchange patterns characterized the interaction in the transcript?

- What (if anything) do the patterns suggest about the nature of interpersonal communications and interaction in this conference?

\section{The conference and the transcript}

The transcript used in the study was generated by 13 students and an instructor (one of the authors), all experienced users of computer conferencing in academic settings. The 15-week graduate course in which the interaction occurred was an elective within Athabasca University's Master of Distance Education program, and was offered entirely at a distance. Interaction was achieved by e-mail, file

International Review of Research in Open and Distance Learning 
exchange for submission of and feedback on assignments and projects, a course Website, and computer conferencing. The complete 53,671-word conference transcript (44,599 words posted by students) was coded by one of the authors, while the other authors coded portions for comparison and the validation trials (below).

The instructor moderated the conference, and provided conference starter messages in each unit, in the form of three initial questions or topics, to which participants could respond. Participation in the conference was worth $10 \%$ of the course mark; full marks were awarded if a student posted a minimum of two contributions in each of the seven course units (a total of 14 postings). At the start, students were advised that conference transcripts would be archived and would later be used in research. Students could request that any of their postings be removed from the conference or revised at any time prior to archiving of the conference at course-end. (No requests for editing or removal of posts were received.)

The instructor attempted to model diligent conference participation, accounting for 106 of 462 total postings (23\%), and 9,072 of 53,671 total words (17\%). (Standards for interpreting this level of involvement are elusive. Shank [2001] suggests an instructor should make a minimum of $10 \%$ of conference postings, by which criterion the instructor in this course was highly present.)

\section{The TAT}

Our review of previous studies, and experience with other transcript analysis tools, led us to adapt Zhu's (1996) analytic model (Fahy, et al., 2000; Fahy, 2001a), resulting in the Transcript Analysis Tool (TAT). Three trials were conducted by the course authors, using the TAT in various applications. Trial 1 , which achieved $86 \%$ agreement, was an intra-rater (code-recode) design conducted by one of the authors. In this trial, ten days elapsed between the initial coding and subsequent recoding. The agreement rate was calculated as the simple proportion of agreement from coding to recoding. Trials 2 and 3 involved all three authors. In these cases, agreement was calculated both by the ratio of concordant ratings, and by application of Cohen's kappa to selected trials. (Kappa is a chance-corrected measure of agreement, where 1.0 indicates perfect agreement) (Agreement observer, 2000; University of Colorado, 1999).

By the measure of concordant codings, agreement rates among the three raters of $60 \%$ (trial 1) and $71 \%$ (trial 2) were achieved. On another trial coding, kappa values of 0.45 and 0.65 for pairs of raters on two separate samples were achieved. (Chuang, 2001, suggests these could be seen as evidence of moderate and substantial agreement, respectively, although he adds that this is only a "rough guide" to interpretation of kappa values). The participants in the agree- 
ment trials concluded that proficiency increased rapidly with experience, and further practice with the instrument would likely result in further increases in agreement.

The TAT was designed to permit transcript content to be coded reliably and efficiently. The TAT's primary and secondary categories are presented in Table 1 (see Attachment A for definitions, and examples from the transcript illustrating each category).

Table 1: Primary and secondary categories in the Transcript Analysis Tool (TAT)

\begin{tabular}{|l|l|}
\hline \multicolumn{1}{|c|}{ Primary Categonies } & \multicolumn{1}{c|}{ Secondary Categonies } \\
\hline \multirow{2}{*}{ T1 - Questioning } & T1(a): vertical \\
\cline { 2 - 2 } & T1(b): horizontal \\
\hline \multirow{2}{*}{ T2 - Statements } & T2(a): direct \\
\cline { 2 - 2 } & T2(b): answers or comments \\
\hline \multirow{2}{*}{ T3 - Reflections } & \\
\hline \multirow{2}{*}{ T4 - Scaffolding } & T5(a): references, quotations, \\
\hline \multirow{2}{*}{ T5 - References, authorities } & Paraphrases \\
\cline { 2 - 2 } & T5(b): citations or attributions \\
\hline
\end{tabular}

ATLAS.ti(c), a qualitative analysis software package, was used to facilitate transcript coding and analysis.

\section{Findings}

The study's findings are reported here in relation to structural and interactional elements of the transcript. The structural features discussed are network size, density and intensity; interactional features are reflected in the TAT analysis of sentence types found within the transcript. 


\section{Structural features}

The basic structural features of the online conference network described the characteristics of the network itself. From this analysis came information about the scope for potential interaction, as well as data on the actual extent to which individuals connected and interacted online. (No attempt was made to assess other types of contact among group members, such as telephone, e-mail, or faceto-face interaction. The following analysis refers only to interaction preserved in the transcript of the course computer conference.)

\section{Network size}

The network in this study was modest in size, consisting of 13 students (6 women and $7 \mathrm{men}$ ), and the instructor. (While the small size of the group obviously affected generalizability, it was desirable in an exploratory study.) As no student chose an alternate activity to replace the course conferencing requirement, all students were members of the online network, and each student thus potentially had a total of 12 other students (and the instructor) with whom to interact.

The influence of network size on interaction is direct: as the size of the network grows arithmetically, the number of potential linkages grows proportionally. (For this group of 13 students, the number of potential person-to-person links was 78; if the instructor is added to the possible links, the number rises to 91 . For a group of 15 the number is 105, for a group of 25 it is 300 , and for a group of 50 the total is 1,225 .) Clearly, size is a major structural determinant of what level of involvement is feasible for a given network. Group size is also important because it is used in the calculation of other network parameters (Ridley \& Avery, 1979). If some students are not actually involved in the network (because they have chosen an alternative activity, for example), their absence should be reflected in the value for size.

\section{Density}

The density of network communication (the ratio of the actual number of connections observed, to the total potential number of possible connections) was calculated to assess the level of person-to-person linkage. (Density, it should be noted, may have been somewhat affected by the fact that there was a minimum course requirement for participation. However, while students were required to contribute to the conference, no specific direction was given about with whom they should interact.)

Various definitions of the term density, and differing methods for calculating it, have been proposed (Ridley \& Avery, 1979). Berkowitz's (1982, p. 45) formula 
was used here:

$\operatorname{Density}(\mathrm{D})=2 \mathrm{a} / \mathrm{N}(\mathrm{N}-1)$

where $\mathrm{a}=$ the actual number of interactions observed (61), and $\mathrm{N}=$ the number of participants in the network (13).

Using these values in the above formula, the density of this network was calculated at 0.782 , or $78 \%$.

Density is a measure of the breadth of social experience of the individuals in any group (Berkowitz, 1982), and may also be seen as a measure of connectedness within the network. (Connectedness here means linkages between pairs of network members, occurring as a result of either party's initiative.) Density may be useful in determining how well a group of people "mixed" or connected, but some caveats apply to its interpretation. First, high values for density can result from the efforts of a small number of "connectors" reaching out to others in the network. If this were to occur, density values would be inflated, while the average number of connections of all network members (the degree of the network, a measure of how "democratic" interaction was) would be low. In fact, such a pattern was observed here: the average number of contacts in the network was 6.9 , or about $58 \%$ of its possible maximum (12), while the density, as shown above, was $78 \%$ of its possible maximum value. We conclude, therefore, that a relatively small number of participants accounted for a large part of the interaction. (More evidence is presented below for this interpretation, in the discussion of intensity.)

Another caveat is that network density is highly associated with network size, and density figures in larger networks are predictably lower than in smaller ones. Comparisons of density values should not be made between groups of different sizes as a way of inferring network connectedness (Rytina, 1982).

\section{Intensity}

While density shows the number of links among all individual network members, intensity is reflected in the depth and persistence of the interaction. Intensity implies the participants are actually engaged, rather than merely dutiful. (Density suggests the presence of dutiful behaviour: participants politely "checking in" with each other, but failing to engage.) Intensity is one of the better measures of involvement in the interaction itself, because it measures dedication and persistence and not mere one-time contact (Ridley \& Avery, 1979). Evidence of the competence of the analytic method to measure intensity was of special interest in this study.

Levels of participation. A major indicator of intensity in this network was the degree to which, on average, participants exceeded the minimum course

International Review of Research in Open and Distance Learning 
requirement for conference participation. As noted above, while the requirement was 14 postings the average number of student postings was 26 . Thus, the average number of student postings was 195\% of the requirement (356 postings were made by students, where 182 would have met the requirement).

$S-R$ ratio. In order to assess further the parity (and quantify the disparity) of the interaction among individuals in the network, a proportion of "messages sent" over "messages received" (the S-R ratio) was calculated for each member. The $\mathrm{S}-\mathrm{R}$ ratio for the students was 1.59 , indicating that, as a group, participants sent about one and one-half messages for each message received. (The instructor's $\mathrm{S}-\mathrm{R}$ ratio was 0.43 , indicating receipt of more than two messages for each one sent.)

At the level of individual participants, the S-R ratio confirmed the considerable variability in communication intensity already mentioned. The range in the S-R ratio was striking: from a high of 2.7 (a student who made 16 postings) to a low of 1.0 (a student who made 22 postings). Examination of the S-R ratios for individuals confirmed that reaching out to touch others did not necessarily result in reciprocation: the individual who was most highly connected (the student with the widest number of contacts, who had interacted with 12 others in the group) did not receive replies from 6 of those she contacted. (Her S-R ratio was a relatively high 2.1 , compared to the average group S-R value of 1.6).

Persistence. Another measure of intensity, or the conference's "pull," was found in the participants' persistence in the interaction, shown by the level to which topics were pursued. The term level as used here means how many messages appeared in the "thread" of a discussion, from the first posting on the topic to the last. The level to which a topic had progressed was readily apparent to participants, as part of the structure of the transcript. Levels of posts appeared as follows in the transcript:

Initial posting

Level 2

Level 3

Level 4

Etc.

Topical progression suggests that as a discussion continues it will move away from the original focus (the discourse topic), and may, if continued long enough,

International Review of Research in Open and Distance Learning 
evolve to a discussion of a completely different topic, just as a spoken conversation might (Witte, 1983). Even if they are aware of this "drift," participants may not choose to recognize it by beginning a new sequence, because doing so might interrupt the thread of the discussion. Instead, they may choose to continue the discussion, posting to each other's comments and extending the discussion to deeper levels, all the while perhaps moving further away from the original topic. Whether topics drift or not, the fact of persistence in the discussion was seen as indicating engagement reflective of the intensity within the interaction.

Examination of levels achieved in the transcript, shown in Table 2, revealed the extent to which discussions persisted: more than $20 \%$ of all postings went beyond the fifth level, while about a third stopped by Level 2. As there is little directly comparable information in this area, Levin, Kim and Riel's (1990) experience with the culturally heterogeneous and international "Intercultural Learning Network" (ILN) are also shown in the table, for contrast.

Table 2: Persistence in student topic development

\begin{tabular}{|c|r|r|c|}
\hline Topic terminated at: & $\#$ & $\%$ & Levin et al. (\%) \\
\hline Level 1 & 2 & 1 & 54 \\
\hline Level 2 & 126 & 35 & 24 \\
\hline Level 3 & 47 & 13 & 13 \\
\hline Level 4 & 70 & 20 & 6 \\
\hline Level 5 & 33 & 9 & 3 \\
\hline Level 5+ & 78 & 22 & 1 \\
\hline
\end{tabular}

Clearly, the participants in this study showed more persistence than was observed by Levin et al. This might reflect the impact of size on persistence (the ILN group was much larger). It may also indicate the importance of structure and moderator presence (the ILN was an electronic message system - a bulletin board - rather than a moderated computer conference). Whatever the explanation, it is clear that persistence is another variable on which participation and participants differed here.

Another observation about persistence, providing further insight into the individual variability of intensity, was that the participants who made fewer postings overall also tended to make them earlier in the conference and were thus less persistent. The two individuals who made the fewest postings overall (13 and 16) made $72 \%$ of their contributions (21 of 29 ) in Levels 2 or 3, and only $14 \%$ (4 of 29) at Level 6 or higher. In comparison, the two students who made the 
highest number of postings (47 and 39) made $29 \%$ of their postings at Levels 2 and 3 ( 25 of 86$)$, and $30 \%$ at Level 6 or higher.

Persistence reflected the personal investment of some participants in the conferences more than simple numbers of postings did, because both implied commitment of time and energy over time. Persistent participants actually interacted; they did not simply log-in, post and leave, oblivious of others.

In network theory, in order to participate in a conference other opportunities for interaction of different kinds must be foregone; membership in a network is seen as both facilitating and limiting, permitting and restricting. Commitment to a network affects the kinds of interaction, range of topics, and the eligible individuals with whom one might interact (Ridley \& Avery, 1979). Within a structured conferencing setting such as obtained here, early contributions may be seen as preferable by some because it is easier to make original observations when there are fewer postings already there. For those less inclined to interact, or less engaged in the topic, there is also less to connect with: Level 1 comments do not have to relate to a potentially extensive existing discussion. Since all participants met the minimum requirements of the conference, none can be said to have been insufficiently connected to the network. The fact that some greatly exceeded the minimum, and how they did so in various ways, is a notable finding from the analysis of the structural components of the transcript.

\section{Interactional features of the conference}

Interactional characteristics of the network were addressed by TAT analysis of the types of content in the transcript. (See Attachment A for definitions and examples of TAT categories.)

\section{The TAT analysis of transcript content.}

The frequency of each of the TAT types in this transcript is shown in Table 3. The number of sentences is shown for students' postings only.

To facilitate comparisons, Table 4 presents occurrences of each TAT type per thousand words.

Gender patterns were not the focus of this study (see Fahy, 2001b, for a fuller treatment of this question), but some intriguing differences emerged from the above. Women were more likely to ask questions of both types (types $1 \mathrm{~A}$ and 1B), and were also somewhat more likely to answer questions and to refer to previous material in their postings (type $2 \mathrm{~B}$ ). Men, on the other hand, were somewhat more likely to cite authorities in the form of quotations or para-

International Review of Research in Open and Distance Learning 
Table 3: Frequency of TAT types

\begin{tabular}{|l|r|r|c|c|c|c|}
\hline \multicolumn{1}{|c|}{ TAT Types } & \multicolumn{2}{c|}{ Men } & \multicolumn{2}{c|}{ Women } & \multicolumn{2}{c|}{ Total } \\
\hline & $\#$ & $\%$ & $\#$ & $\%$ & $\#$ & $\%$ \\
\hline 1A: Vertical questions & 9 & 35 & 17 & 65 & 26 & 1 \\
\hline 1B: Horizontal questions & 21 & 45 & 26 & 55 & 47 & 2 \\
\hline 2A: Expository statements & 593 & 45 & 736 & 55 & 1329 & 52 \\
\hline 2B: Referential statements & 104 & 42 & 142 & 58 & 246 & 10 \\
\hline 3: Reflections & 241 & 46 & 285 & 54 & 526 & 21 \\
\hline 4: Scaftolding, engajing & 88 & 35 & 164 & 65 & 252 & 10 \\
\hline $\begin{array}{l}\text { 5A: Quotations, } \\
\text { Paraphrases }\end{array}$ & 47 & 53 & 42 & 47 & 89 & 3 \\
\hline 5B: Citations & & & & & & \\
\hline Total & 27 & 63 & 16 & 37 & 43 & 2 \\
\hline
\end{tabular}

phrases (type 5A), and were considerably more likely to include citations in their postings (type $5 \mathrm{~B}$ ).

These differences were small compared with the overall uniformity of the pattern of conference interaction revealed by the TAT: type $2 \mathrm{~A}$ sentences (statements) predominated at $52 \%$, followed by type 3 (reflections) at $21 \%$; together, these two types accounted for almost three-quarters (73\%) of the sentences in the transcript. Scaffolding and engaging (type 4) and references to others' posts (type 2B), at 10\% each, accounted for another fifth of the interaction. Questions of both types, and quotations, paraphrases and citations, together accounted for the remainder $(8 \%)$.

\section{Discussion}

Two questions were posed to guide this study. First, what structural and interactional exchange patterns characterized the interaction in the conference? Second, what do the patterns suggest about the nature of interpersonal communications and interaction in this conference? 
Table 4: Occurrences of TAT types per 1000 words

\begin{tabular}{|l|c|c|c|}
\hline \multicolumn{1}{|c|}{ TAT Type } & Men & Women & Total \\
\hline 1A: Vertical questions & 0.41 & 0.67 & 0.53 \\
\hline 1B: Horizontal questions & 0.97 & 1.09 & 1.02 \\
\hline 2A: Expository statements & 28.63 & 30.62 & 29.55 \\
\hline 2B: Referential statements & 5.00 & 6.42 & 5.65 \\
\hline 3: Reflections & 11.56 & 11.86 & 11.70 \\
\hline 4: Scaftolding, engaging & 4.13 & 7.60 & 5.73 \\
\hline 5A: Quotations, paraphrases & 2.35 & 1.76 & 2.08 \\
\hline 5B: Citations & 1.38 & 0.74 & 1.08 \\
\hline
\end{tabular}

In relation to the first question, the social network concepts used here appeared to provide useful insights into the workings of this online conference. Network size and complexity, for example, showed how important these apparently simply concepts were to the potential for genuine group interaction. Furthermore, considering these structural elements of the network raises questions about the choices students should have in conference participation, including alternatives to network participation. The behaviour of students observed in this study should cause facilitators and moderators of online interaction to consider questions such as the following:

1. Should students, especially those whose connection to the network, for whatever reasons, is likely to be minimal, be offered alternative methods of interaction?

2. What effects does minimal or unwilling social interaction have on the individuals exhibiting it, and on the network?

3. What should our response be to indications that some of our students find network sizes intimidating, or the conferencing experience less satisfying, valuable or personally feasible than we intend?

In this study, no student took advantage of the available alternatives to conferencing. At 13, this group was relatively small for a distance education class, and, as shown, the maximum possible number of interactional combinations for a group this size was relatively small. With even modest increases in size, however, complexity increases dramatically. Obviously, the expectation of what

International Review of Research in Open and Distance Learning 
constitutes realistic participation in (or even awareness of) the whole of the interaction in a conference is affected by these mathematical realities, and should be reflected both in our moderating behaviour and in our requirements for participation. Size limits the number of contacts, and it forces participants to be selective in their interactions. How network participants choose to limit the size of their personal network, and how they select their contacts, is of interest, and we recommend further research in these areas.

Density and intensity measures showed high levels of variability in the participation and connectedness of network members. Again, these findings should raise concern for the apparent experience of the participants. First, it would be unwarranted to conclude that individuals with minimal links to others had deficient social or intellectual experiences. Cook (1982) suggests that the quality of "exchange relations" rather than the quantity of exchange transactions should be the focus of analysis in determining the quality of interrelationships. Future research (for example, using an instrument such as the TAT to assess content in networks of varying density) might illuminate the question of the relation of connectedness measures to other criteria.

Clearly, there were wide variations in the connectedness of individuals within this network, as shown by the discussion of density. Density reflects the degree to which all are acknowledged within the network. The usefulness of densityrelated measures should now be established in relation to core distance education issues such as network health (Kadushin, 1982), cognitive presence (Garrison, Anderson \& Archer, 2001) and social presence (Rourke, et al., 1999), and the relation of interaction to learning itself (Gunawardena et al., 1997).

The desirability and feasibility of multiplex or multi-strand networks arises from analysis of participant behaviour. Participation and connectedness were variable in this study, supporting the practice of permitting participants to diverge from given topics, to form special interest groups, and generally to adapt the conferencing experience to their individual needs. It seems clear that network membership constrains choices (Rytina, 1982). The degree to which it may be possible to create community within a flexible online environment needs to be investigated.

In relation to the second research question posed for this study, the TAT provided information on the interactional aspects of the conference. In this conference, over half of students' sentences were direct statements $(52 \%)$, while the next largest category, reflections, comprised $21 \%$. In relation to the theory of expository and epistolary types (Herring, 1996), this suggests that the predominant discourse type in this conference was expository, oriented to the transfer of information. Reflections, on the other hand, are considered an epistolary type (like a typical friendly letter, affirming the other, aligning with the other's views, and supporting continued dialogue). Further study is needed to determine the usefulness of typologies such as Herring's in analyzing the content of interaction in relation to various outcome measures, including levels and types of 
participation and interaction, and gender differences in online behaviour (Fahy, 2001b.)

Some results of the TAT analysis accorded well with previous transcript research. Herring (1996) reported that $67 \%$ of the statements in her study expressed points of view. In this analysis, Type 2 sentences (statements) comprised the greatest single type, at $62 \%$ of the total. Gunawardena et al.'s (1997) method coded the greatest portion $(92 \%)$ of their corpus as Phase 1 ("sharing and comparing of information" p. 414). These findings suggest consensus that information-related statements are likely to comprise the largest portion of online conferences.

Another corroborating finding related to the relatively rare occurrence of questions in transcripts. Five percent of Herring's statements requested information, while $3 \%$ of statements in this study consisted of questions. There appears to be consensus that questioning constitutes a consistently small fraction of interaction.

Finally, the overall proportion of engaging or scaffolding sentences (10\%) in this study may be compared with other studies, if care is taken in doing so. Rourke et al. (1999), for example, estimated that up to one-quarter of message content might consist of "expressions of feeling, self-introductions, jokes, compliments, greetings and closures" (p. 54). In our study, these kinds of expressions were coded as Type 4, and constituted $10 \%$ of all postings. However, identifying expressions of feeling can be problematic, as in this study they may have been coded Type 3 if they were judged to be reflective. Type 3 constituted $21 \%$ of all postings; if half of these were expressions of feeling the resulting proportion (added to Type 4), at 20\%, is close to what Rourke and his colleagues observed. (In comparison to our findings here, Herring reported that $10 \%$ of statements in her study expressed feelings.)

In regard to the question of the directional flow, or directedness, of interaction within the conference, the variability noted throughout led to the conclusion that interaction here appeared asymmetric and non-complementary. In the absence of information about the participants' motivations and personal outcomes derived from network interaction, their widely differing levels of participation seemed to indicate different levels of purpose, and varying perceptions of benefit. If the online discussion was indeed social, participation or non-participation can be regarded as a judgment about the results: participation suggests benefits were being achieved (Ridley \& Avery, 1979), while non-participation suggests disappointment, or conflicting priorities (Rytina, 1982). On the evidence of this study, the question of the meaning of asymmetric directedness remains open, and in need of further research.

The roots of participant motivation overall remain to be explored. Our analysis found willingness by some to engage in the social network far beyond minimum requirements. The aspects of the network experience which encouraged the 
investment of time and energy, and how these motivators might be detected in network interaction, remain to be determined, a task we suggest may be feasible with the TAT and the other tools used here.

In terms of the TAT itself, this study produced evidence that the TAT was usable for a coding task of the magnitude encountered here (some 53,000 words), especially when used with a computer-based coding and analysis tool. The study demonstrated the capacity of the TAT to discriminate among the types of sentences within the transcript. A weakness of the TAT is the level of interrater agreement demonstrated to date. Further trials need to be conducted to determine how reliable the TAT is under conditions of greater practice. (The apparent intra-rater reliability reported here, and by Keller [1999], suggests that there is potential for high levels of agreement, and thus of reliability, with sufficient training and practice.)

While we suggest further work with our instrument and procedure, we also recognize the possibility that other useful instruments may appear (including an improved TAT). We expect the instrument and procedures to evolve as others (and we) make further uses of them in different applications.

\section{Conclusion}

This study found evidence that the exchange patterns in a conference could be assessed by analysis of a combination of structural and interactional evidence. We also found the tools of network theory were useful and applicable to the analysis of the online interaction in the transcript. As an exploratory study, the analysis raised a number of questions which we are encouraged to think may be addressed in future applications of this analytic method. We recommend that research and experimentation with analytic systems and tools in the area of transcript research should continue. We hope that the issues we articulated and addressed in this paper will generate further comparative data.

We particularly commend to transcript researchers use of objective measures of structural and interactional properties in the analysis of conference networks and transcripts. Our experience here with the concepts and tools of network social interaction was positive, and this encourages us to agree that research methods in this area should be used and questions posed which turn (or return) to "fundamental concepts and constructs" (Saba, 2000). Disciplines which have grappled with the analysis and description of face-to-face interaction potentially have much to offer those who work with interaction in virtual communities. Researchers should regard this work as fundamental, and consider how it might assist us in advancing transcript research.

International Review of Research in Open and Distance Learning 


\section{Attachment A}

\section{TAT Categories and examples}

\section{T1: Questioning:}

Type 1A includes vertical questions, which assume a "correct" answer exists, and the question can be answered if the right answer can be found.

\section{Examples:}

- "Is the presenter involved in producing the script?"

- "What do you do with your questionnaire results at the end?"

- 'Would I be correct in using 'paradigm pioneer' and 'entrepreneur' in the same way, or would there be differences between the two?"

Type 1B are horizontal questions: there may not be one right answer, and others are invited to help provide a plausible or alternate "answer," or to help shed light on the question.

\section{Examples:}

- "What do these indicate about our cultural orientation to 'technology' (as a form of tool-making), and perhaps how this view may have changed over time?"

- "Afterall, what makes a technology advanced?"

- "Just because we put a course online does that mean that is all that learners can have access to, does that mean we have to forget about the great textbooks and other resources that are available?"

\section{T2: Statements:}

Type 2A statements contain little self-revelation and usually do not invite response or dialogue. The main intent is to impart facts or information. The speaker may take a matter-of-fact, a didactic, or even a pedantic stance, providing information or correction to an audience which he or she appears to assume is uninformed or in error, but curious and interested, or otherwise open to information or correction. Statements may contain implicit values or beliefs, but usually these are inferred, and are not as explicit as they are in reflections.

\section{Examples:}

International Review of Research in Open and Distance Learning 
- "In my organization, strategic planning occurs in a focus group of individuals assigned to the organization and development of course material and yearly plan."

- "We found that keeping content up-to-date, distribution and PC compatibility issues were causing a huge draw on Ed. Centre time."

- "Both excellent and learning organizations have similar characteristics."

Type 2B are direct answers to questions, or comments referring to specific preceding statements.

\section{Examples:}

- "I suspect there is a lot of truth in your statement."

- "[Name], this is not the only case, I'm afraid, of a technology being acquired in the assumption that a use would be found for it later."

- "In fact, what you have defined nicely here is 'the learning moment'."

T3: Reflections (significant personal revelations): the speaker expresses thoughts, judgments, opinions or information which are personal and are usually guarded or private. The speaker may also reveal personal values, beliefs, doubts, convictions, and ideas acknowledged as personal. The listener/reader receives both information about some aspect of the world (in the form of opinions), as well as insights into the speaker. Listeners are assumed to be interested in and empathetic toward these personal revelations, and are expected to respond with understanding and acceptance (though the speaker may act somewhat apologetic). The speaker implicitly welcomes questions (even personal ones), as well as self-revelations in turn, and other supportive responses.

\section{Examples:}

- "So, my view is that if a technology is actually better for some purpose than some another technology, it is genuinely 'advanced'."

- "I personally think a specific technology is only obsolete if it is no longer useful."

- "I have often wondered - still do, in fact - why we were not successful."

T4: Scaffolding and engaging: these are intended to initiate, continue or acknowledge interpersonal interaction, and to "warm" and personalize the discussion by greeting or welcoming. Scaffolding and engaging comments connect or agree with, thank or otherwise recognize someone else, and encourage or recognize the helpfulness, ideas and comments, capabilities, and experience of others.

International Review of Research in Open and Distance Learning 
Also included are comments without real substantive meaning ("phatic communion," "elevator/weather talk," salutations/greetings, and closings/signatures), and devices such as obvious rhetorical questions, and emoticons.

\section{Examples:}

- "I hope this gives a little more info. about our methods - let me know if it doesn't."

- "Just a reminder, for those of you who feel overburdened by the CMC requirement (you know who you are!): don’t feel you're alone."

- "Even as a parent and a teacher (with pretty good math skills!) I still learned some new things :-)."

\section{T5: References, authorities:}

Type T5A: references to, and quotations or (fairly direct) paraphrases of other sources.

\section{Examples:}

- "You asked, 'What can you tell about a culture by its tools?",

- "We are told that the medium is sometimes the message."

- "Herbert Simon, Nobel Laureate economist, said, "What information consumes is rather obvious: it consumes the attention of its recipients."'

Type T5B: citations or attributions of quotations or paraphrases.

\section{Examples:}

- "(J. Robert Oppenheimer, Science and the Common Understanding, 1953.)"

- "Max Frisch, Homo Faber, 1957."

- "Phillips, Jack. (1998). The return-on-investment (ROI) process: Issues and trends. Educational Technology, 38, 4, July-August, 7-14." 
Patterns of Interaction in a Computer Conference Transcript

\section{References}

Abrami, P. \& Bures, E. (1996). Computer-supported collaborative learning and distance education. The American Journal of Distance Education, 10(2), $37-42$.

Agreement observer. (2000, October). Chest x-ray. Retrieved March 21, 2001: [http://www.chestx-ray.com/statistics/kappa.html]

Anderson, T. \& Garrison, D. R. (1995). Transactional issues in distance education: The impact of design in audioteleconferencing. The American Journal of Distance Education, 9(2), 27-45.

Berkowitz, S. D. (1982). An introduction to structural analysis. Toronto: Butterworths.

Burt, R. (1983). Distinguishing relational content. In R. Burt \& M. Minor, Applied network analysis (pp. $35-74$ ). London: Sage Publications.

Chuang, J. (2001). Agreement between categorical measurements: Kappa statistics. Retrieved March 21, 2001: [http://www.cpmc.columbia.edu/homepages/ chuangj/kappa/]

Collins, A. (1996). Design issues for learning environments. In S. Vosniadou, E. De Corte, R. Glaser, \& H. Mandl (Eds.), International perspectives on the design of technology-supported learning environments (pp. 347-361). Mahwah, New Jersey: Lawrence Erlbaum Associates, Publishers.

Collins, M. \& Berge, Z. (1996). Facilitating interaction in computer mediated online courses. Retrieved May 30, 2001: [http://jan.ucc.nau.edu/ \char126\relaxmpc3/moderate/flcc.html]

Cook, K. (1982). Network structures from an exchange perspective. In P. Marsden \& N. Lin (Eds.), Social structure and network analysis, (pp. 177 199). Beverly Hills: Sage Publications.

Cookson, P. S. \& Chang, Y. (1995). The Multidimensional Audioconferencing Classification System (MACS). American Journal of Distance Education, $9(3), 18-36$.

Fahy, P. J. (2001a). Addressing some common problems in transcript analysis. International Review of Research in Open and Distance Learning (1)2. Retrieved May 30, 2001: [http://www.irrodl.org/content/v1.2/research. html\\#Fahy]

Fahy, P. J. (2001b). Epistolary and expository interaction patterns in a computer conference transcript. Manuscript submitted for publication.

International Review of Research in Open and Distance Learning 
Fahy, P. J., Crawford, G., Ally, M., Cookson, P., Keller, V. \& Prosser, F. (2000). The development and testing of a tool for analysis of computer mediated conferencing transcripts. Alberta Journal of Educational Research, 46(1), $85-88$.

Fulford, C. P. \& Zhang, S. (1993). Perception of interaction: The critical predictor in distance education. The American Journal of Distance Education, $7(3), 8-21$.

Garrison, D. R. (1989). Understanding distance education: A framework for the future. New York: Routledge.

Garrison, D. R., Anderson, T., \& Archer, W. (2001). Critical thinking, cognitive presence, and computer conferencing in distance education. The American Journal of Distance Education, 15(1), 7-23.

Gibson, C. C. (1996). Collaborative learning in action via computer mediated conferencing. In Proceedings of the 12th Annual Conference on Distance Teaching and Learning: Designing for Active Learning, (pp. 121-125). Madison: University of Wisconsin.

Gunawardena, C., Lowe, C. \& Anderson, T. (1997). Analysis of a global on-line debate and the development of an interaction analysis model for examining social construction of knowledge in computer conferencing. Journal of Educational Computing Research, 17(4), 397-431.

Haughey, M. \& Anderson, T. (1998). Networked learning: The pedagogy of the internet. Montreal: Chenelière/McGraw-Hill.

Henri, F. (1992). Computer conferencing and content analysis. In A. Kaye (Ed.), Collaborative learning through computer conferencing: The Najaden papers (pp. 117-136). Berlin: Springer-Verlag.

Herring, S. (1996). Two variants of an electronic message schema. In S. C. Herring (Ed.), Computer-mediated communication (pp. 81-106). Philadelphia: John Benjamins Publishing Co.

Jonassen, D. (1999). Designing constructivist learning environments. In C.M. Reigeluth (Ed.), Instructional design theories and models, Volume II: A new paradigm of instructional theory. (2nd ed., pp. 215-239). Mahwah, NJ: Lawrence Erlbaum.

Kadushin, C. (1982). Social density and mental health. In P. Marsden \& N. Lin (Eds.), Social structure and network analysis, (pp. $147-158)$. Beverly Hills: Sage Publications.

Kanuka, H. \& Anderson, T. (1998). Online social interchange, discord, and knowledge construction. Journal of Distance Education, 13(1), 57-74. 
Keller, V. (1999). Adaptation and application of a transcript analysis tool to analyze a computer-mediated communication $(C M C)$ distance education course transcript. Unpublished master's thesis, Athabasca University, Athabasca, Alberta.

Levin, J., Kim, H. \& Riel, M. (1990). Analyzing instructional interactions on electronic message networks. In L. Harasim (Ed.), Online education (pp. 185 - 213). New York: Praeger.

Morris, R.M., Mitchell, N. \& Bell, M. (1999). Student use of computer mediated communication in an Open University level 1 course: Academic or social? Journal of Interactive Media in Education, 99(2). Retrieved May 30, 2001: [http://www-jime.open.ac.uk/99/2/]

One-third of workday on computer, study says. (2000, February 26). The Edmonton Journal, p. I10.

Ridley, C. \& Avery, A. (1979). Social network influence on the dyadic relationship. In R. Burgess, \& T. Huston, (Eds.). Social exchange in developing relationships. (pp. 223-246). New York: Academic Press.

Rourke, L., Anderson, T., Garrison, R. \& Archer, W. (1999). Assessing social presence in asynchronous text-based computer conferencing. Journal of Distance Education, 14(2), 50-71.

Rytina, S. (1982). Structural constraints on intergroup contact. In P. Marsden \& N. Lin (Eds.), Social structure and network analysis, (pp. 81 - 100). Beverly Hills: Sage Publications.

Saba, F. (2000). Research in distance education: A status report. International Review of Research in Open And Distance Learning (1)1. Retrieved December 21, 2000: [http://www.irrodl.org/content/v1.1/farhad.pdf]

Shank, P. (2001). Asynchronous online learning instructor competencies. Retrieved March 6, 2001: [http://www. learningpeaks . com/instrcomp.html]

University of Colorado. (1999). Calculating Cohen's Kappa. Retrieved March 21, 2001: [http://www. Colorado.EDU/geography/gcraft/notes/manerror/ html/kappa.html]

Wellman, B. (1982). Studying personal communities. In P. Marsden \& N. Lin (Eds.), Social structure and network analysis (pp. $61-80$ ). London: Sage Publications.

Witte, S. (1983). Topic structure and revision: An exploratory study. College Composition and Communications, 34(3), 313-341.

Zhu, E. (1996). Meaning negotiation, knowledge construction, and mentoring in a distance learning course. In Proceedings of Selected Research and De- 
velopment Presentations at the 1996 National Convention of the Association for Educational Communications and Technology. Indianapolis, IN. (ERIC Document Reproduction Service No. ED 397 849)

Citation Format

Fahy, Patrick J., Crawford, Gail \& Ally, Mohamed (July, 2001) Patterns of Interaction in a

Computer Conference Transcript. International Review of Research in Open and Distance

Learning: 2, 1. http://www.icaap.org/iuicode?149.2.1.4

International Review of Research in Open and Distance Learning 